\title{
ANALISIS FAKTOR-FAKTOR YANG MEMPENGARUHI NIAT PEMBELIAN SEPATU OLAHRAGA BERMERK MEWAH DI KOTA BATAM
}

\author{
Edy Yulianto Putra ${ }^{1)}$, Agustina Fitrianingrum ${ }^{2)}$ \\ ${ }^{1}$ Fakultas Ekonomi, Universitas Internasional Batam, Jalan Gajah Mada, Sei Ladi, Tiban Indah, \\ Sekupang, Kota Batam, Kepulauan Riau 29442 \\ Email: yulianto@uib.ac.id ${ }^{1)}$, agustina@uib.ac.id ${ }^{2)}$
}

\begin{abstract}
Abstrak
Merek mewah menjadi faktor yang mempengaruhi niat pembelian, kemudian dengan adanya pengaruh sosial yang memicu, dan juga pengaruh dari faktor kebanggaan dalam memiliki produk bermerek mewah menjadikan niat pembelian tinggi. Tujuan penelitian ini adalah untuk mengetahui pengaruh merek mewah, pengaruh sosial, kemudian kebanggaan sebagai variabel yang mengintervensi dalam pengaruhnya terhadap niat pembelian konsumen dalam membeli produk sepatu olahraga di Kota Batam. Penelitian ini dilakukan dengan menggunakan structural equational modelling yang meneliti pengaruh variabel-variabel independen terhadap variabel intervening dan dependen, kemudian variabel intervening mempengaruhi variabel dependen. Sampel dalam penelitian ini sebanyak 188 responden dari gerai penjualan sepatu olahraga yang ada di pusat-pusat perbelanjaan di Kota Batam. Teknik penarikan sampel menggunakan convinience sampling. Sampel yang digunakan dalam penelitian ini adalah konsumen yang mengunjungi gerai resmi penjualan sepatu olahraga yang ada di pusat perbelanjaan di Kota Batam.
\end{abstract}

Kata Kunci: Merek Mewah, Pengaruh Sosial, Kebanggaan, Niat Pembelian.

\begin{abstract}
Sport and luxury of branded shoes seem have a bromance for younger generation. It is one of promising areas to explore since number of younger generation is $60 \%$ of Indonesia's population. Luxury brand is predicted to be an influencer of consumers' willingness to buy. However, it doesn't come as a single factor as social influence and vanity are predicted signify their relationship to willingness to buy. The purpose of this study is to validate the present of vanity as a mediating of luxury brand and social influences to willingness to buy of branded shoes of young customers in Batam. Batam is chosen as the place of the research because Batam is representing a fast growing metropolitan city in Indonesia. The fashion style of younger generation refer to Singapore and Malaysia as neigbourhood countries. Data collected is then analysed using SEM PLS which involving 188 respondens who visited the official outlets of branded sport shoes in shopping centers in Batam. The data shown that luxury brand and social influence are validate as significant predictors of willingness to buy. However, vanity is only partialy mediate the relationship between those variables.This fact finding should be considered to strengthen strategy toenhance brand awareness among younger generation who prefer to wear branded sporty fashion style.
\end{abstract}

Keywords: Luxury Brand, Social Influences, Vanity, Willingness to Buy

\section{PENDAhuluan}

Merek mewah telah menjadi icon untuk masyarakat yang teridentifikasi misalnya untuk merek mewah jam tangan seperti Rolex, Swiss Army, Alexandre Christie, kemudian untuk produk sepatu olahraga seperti Nike, Adidas, Reebok, Converse, Airwalker. Karakteristik merek mewah menurut (I.Cheah, I.Phau, C.Chong, 2015) terdiri dari adanya identitas yang kuat (strong identity), kesadaran yang tinggi (high awaraness), keterlibatan emosional (emotional attachment) bagi konsumen yang menggunakan merek mewah. Menurut (D'Arpizio, Levato, Zito, \& De
Montgolfier, 2014) yaitu sebuah survey mengenai konsumsi produk merek mewah yang menyatakan bahwa penjualan produk mewah di dunia telah meningkat sebesar 7\% di tahun 2014 atau senilai dengan 850 milyar Euro. Hal ini meliputi penjualan beragam produk mulai dari jam tangan, perhiasan, pakaian termasuk sepatu, anggur, mobil, dan kapal /yachts. Merek mewah bukan hal yang baru muncul, pada abad ke tujuh belas, produk merek mewah ditemukan dalam komoditas yang berupa mutiara, kristal, dan parfum. Semenjak awal abad ke dua puluh, merek mewah lebih bersifat seperti produk pakaian, dan produk 
buatan dari para pemilik desain (P.Berthon, L.Pitt, M.Parent, 2009). Bukan hanya di Eropa, tingkat pembelian produk dengan merek mewah berkembang sangat pesat di Asia (Teimourpour \& Heidarzadeh Hanzaee, 2011). Status sosial dan gaya hidup memiliki peranan penting dalam mempengaruhi konsumen untuk membeli produk bermerek mewah. Pembelian produk merek mewah adalah sebagai simbol yang mewujudkan status sosial bagi pembelinya. (Hung et al., 2011) menyatakan bahwa konsumen yang menggunakan produk bermerek mewah memiliki tujuan untuk menunjukkan adanya status sosial yang mereka tampilkan dan secara simbolis melambangkan kekuatan ekonomi pemakainya, merek mewah atau luxury brand memiliki nilai tersendiri karena nilai tersebut memberikan kelebihan bagi konsumen yang membeli dan memakai produk merek mewah tersebut. Perkembangan teknologi informasi termasuk di bidang fashion yang meliputi baju dan sepatu serta aksesoris lainnya mempercepat pergerakan mode bagi muda-mudi di Batam. Konsumen yang berusia mulai dari 18 tahun ke atas, termotivasi untuk mengikuti gaya fashion yang menjadi trend, karena masyarakat segmen ini sudah memiliki kebebasan untuk menggunakan fashion yang mereka sukai.

Hal ini juga dikemukakan oleh penelitian yang dilakukan oleh (I.Cheah, I.Phau, C.Chong, 2015) dimana merek mewah menjadi sangat penting dalam fashion, lebih lanjut merek menjadi pusat perhatian konsumen dalam membeli, merek memegang peranan penting dalam mempengaruhi pembelian konsumen terhadap barang mewah, merek yang terkenal menjadikan masyarakat yang mengkonsumsi produk merek mewah tersebut membedakan diri mereka yaitu melalui keunikan, dan merek itu sendiri. Penjualan merek mewah berubah seiring dengan perkembangan pemasaran modern, pada kondisi saat ini peminatan anak muda akan merek mewah dan branded sangat tinggi. Menurut Juggessur dan Cohen (2009) dalam penelitian (Doss F., 2013) bahwa konsumen muda yang membeli produk dengan merek mewah (young luxury consumer) adalah segmen yang berkembang sangat pesat dalam pasaran merek mewah (luxury market), konsumen muda lebih memiliki permintaan yang tinggi akan merek mewah dan juga mengikuti trend fashion yang sedang viral atau hype. Kesenangan konsumen muda akan produk bermerek mewah salah satunya yaitu pada produk sepatu olahraga yang bermerek menjadi salah satu simbol yang digunakan oleh konsumen muda untuk menunjukkan eksistensi diri bahwa mereka berasal dari kelas sosial tingkat atas (G. Timperio, Tan K.Chuan, L.Fratocchi, 2016). Berdasarkan pengamatan yang dilakukan oleh peneliti di pusat perbelanjaan di kota Batam, peneliti menemukan bahwa rata-rata banyak pengunjung yang menggunakan sepatu olahraga sebagai kesehariannya ataupun mode. Berdasarkan data penghargaan top brand award for teen Indonesia, merek sepatu-sepatu sport yang sering dibeli adalah dapat dilihat pada tabel 1 .

Tabel 1

Data Survey Sepatu Sport Top Brand Award di Indonesia

\begin{tabular}{ll}
\hline Merek & $\begin{array}{l}\text { Top Brand } \\
\text { Index }\end{array}$ \\
\hline Nike & $44,0 \%$ \\
Adidas & $24,1 \%$ \\
Reebok & $7,7 \%$ \\
Converse & $6,5 \%$ \\
Fila & $1,6 \%$ \\
Total pengguna & $100 \%$ \\
\hline
\end{tabular}

Sumber: Top Brand Award (2016)

Pemakaian sepatu olahraga memang sangat diminati oleh kalangan muda-mudi, hal ini menjadikan mereka memiliki refleksi tersendiri. Aspek kategori merek mewah (luxury brand) sangat merefleksikan perhatian yang meliputi adanya identitas yang kuat, kesadaran yang tinggi, eksklusif (I.Cheah, I.Phau, C.Chong, 2015). Menurut (Martinez \& Kim, 2012) barang mewah seperti pakaian, aksesoris, tas, sepatu, perhiasan, dan parfum, tidak hanya mengutamakan dalam hal kualitas tetap juga menjadi bagian dari identitas konsumen sehingga produk Fashion mewah khususnya dalam produk sepatu olahraga telah menjadi suatu fenomenal yang mempengaruhi muda-mudi di Batam dalam hal berpenampilan. Hal ini bisa kita lihat ketika kita berada di pusat perbelanjaan, para muda-mudi berpenampilan mengikuti mode yang ada saat ini. Produk-produk sepatu sport seperti contohnya Nike, Adidas, Reebok, Converse, Airwalk, Fila menjadi suatu trend untuk muda-mudi dalam berpenampilan, selain terkesan mewah, juga nyaman untuk dipakai, kemudian menimbulkan prestige tersendiri.

\section{TINJAUAN PUSTAKA}

Konsep pemasaran produk bermerek mewah pada segmen masyarakat kelas menengah ataupun dibawahnya disebut dengan "demokratisasi" pada merek mewah (luxury brand) (Srinivasan, Srivastava, \& Bhanot, 2014).

Teimourpour \& Heidarzadeh Hanzaee, (2011) melakukan penelitian mengenai produk dengan merek mewah (luxury brand), produk dengan merek mewah lebih menunjukkan peranannya dalam mensinyalkan status dari pemakai tersebut, hal ini menunjukkan bahwa pengaruh sosial (social influences) sangat berpengaruh sehingga konsumen membeli produk dengan merek mewah, membeli produk mewah menunjukkan status kepada sosial bahwa mereka memiliki kekuatan pembelian (purchasing power). 
Penelitian (Hung et al., 2011) menyebutkan dalam membeli produk bermerek mewah, konsumen memiliki niat pembelian dikarenakan ingin menunjukkan kepada sosial bahwa mereka ingin menunjukkan kebanggaan mereka (vanity), kekuatan pembelian, dan ingin diterima oleh sosial, hal ini yang menjadikan niat pembelian produk bermerek mewah dipengaruhi oleh sosial (social influences). Senada dengan penelitian yang dilakukan oleh (Godey et al., 2013) bahwa pengaruh sosial (social influences) sangat berpengaruh terhadap niat pembelian pada produk bermerek mewah.

Kebanggaan (vanity) memiliki keterkaitan dengan pengaruh sosial (social influences) dan juga berpengaruh terhadap niat pembelian konsumen dalam pembelian produk bermerek mewah. Menurut Wang dan Waller (2006) dalam (Hung et al., 2011) kebanggaan (vanity) memiliki ketertarikan tersendiri dalam menghubungkan terhadap niat pembelian konsumen. (P.Berthon, L.Pitt, M.Parent, 2009) mengemukakan bahwa kebanggaan memiliki implikasi terhadap niat pembelian, kebanggaan memiliki koneksi antara diri konsumen dimana konsumen memiliki keinginan secara simbolis dan pemenuhan kepemilikan produk bermerek mewah.

Menurut penelitian Durvasula (2001) dalam (Park, Rabolt, \& Sook Jeon, 2008) bahwa kebanggaan (vanity) memiliki keterkaitan erat dengan niat pembelian (willingness to buy), konsumen merasa bangga memiliki produk bermerek mewah yaitu bangga secara fisik atau penampilan (physical) dan juga bangga karena memiliki (achievement). (P.Berthon, L.Pitt, M.Parent, 2009) mengemukakan bahwa konsumen dalam membeli produk bermerek mewah dikarenakan mereka ingin memiliki rasa kebanggaan (vanity) karena dengan memiliki produk bermerek mewah, konsumen akan merasakan penampilan mereka yang berbeda dengan yang lainnya sehingga ini menjadikan konsumen memiliki niat pembelian dalam membeli produk bermerek mewah. Berdasarkan tinjauan landasan teori dan penelitian terdahulu, maka dapat dirumuskan model penelitian seperti yang tertera dalam gambar 1 berikut ini.

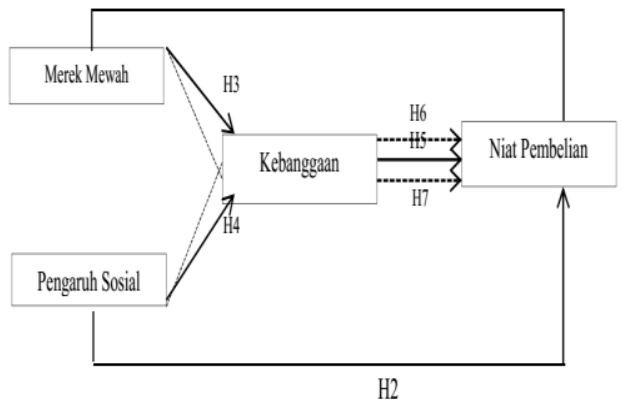

Gambar 1 Model Penelitian
Keterangan: Garis putus-putus: hubungan

intervening.

Sumber: Peneliti (2017), (Cheah \& Phau, 2015), (Hung et al., 2011), (P.Berthon, L.Pitt, M.Parent, 2009)

Berdasarkan pemaparan yang telah dijelaskan sebelumnya dipaparkan maka hipotesis dalam penelitian ini adalah sebagai berikut:

H1. Merek mewah berpengaruh positif dan signifikan terhadap niat pembelian.

H2. Pengaruh sosial berpengaruh positif dan signifikan terhadap niat pembelian.

H3. Merek mewah berpengaruh positif dan signifikan terhadap kebanggaan.

H4. Pengaruh sosial berpengaruh positif dan signifikan terhadap kebanggaan.

H5. Kebanggaan berpengaruh positif dan signifikan terhadap niat pembelian.

H6. Merek mewah berpengaruh positif dan signifikan terhadap niat pembelian dengan kebanggaan sebagai variabel intervening.

H7. Pengaruh sosial berpengaruh positif dan signifikan terhadap niat pembelian dengan kebanggaan sebagai variabel intervening

\section{METODE PENELITIAN}

Menurut Kuncoro (2013) desain penelitian pada hakikatnya mencakup abstraksi isi dan ruang lingkup, desain penelitian tergantung pula dari pendekatan yang digunakan pada subjek penelitian yang berkaitan dengan eksistensi variabel yang diteliti, eksistensi variabel yang dimaksud apakah variabel yang akan diteliti dimunculkan secara sengaja oleh peneliti dalam suatu penelitian atau variabel yang diteliti adalah variabel yang telah ada secara wajar pada subjek yang diteliti.

Desain penelitian yang digunakan dalam penelitian ini adalah desain penelitian kausalitas. Sekaran dan Bougie (2010) mengemukakan desain penelitian kausalitas adalah desain penelitian yang disusun untuk meneliti kemungkinan adanya hubungan sebab-akibat antar variabel, dalam desain ini umumnya hubungan sebab-akibat tersebut sudah dapat diprediksi oleh peneliti, sehingga peneliti dapat menyatakan klasifikasi variabel penyebab, variabel antara, dan variabel terikat. Populasi dalam penelitian ini adalah mengacu pada pengunjung gerai-gerai penjualan sepatu olahraga seperti gerai resmi Adidas di Nagoya Hill Mall, kemudian gerai resmi Nike di Mega Mall, dan gerai Sport Station yang tersebar di BCS Mall, Nagoya Hill Mall, Mega Mall dan juga Kepri Mall. Pengambilan populasi ini dikarenakan konsumen yang berkunjung jelas akan memiliki niat pembelian terhadap sepatu olahraga.

Teknik pengambilan sampel yang digunakan pada penelitian ini adalah teknik convenience sampling, teknik pengambilan sampel ini 
digunakan untuk memberikan kemudahan terhadap peneliti, kemudian pengambilan sampel ini juga berdasarkan aspek efektif dan efisien, peneliti hanya menghentikan seseorang yang berkunjung ke gerai penjualan sepatu olahraga yang menjadi objek penelitian kemudian peneliti meminta izin kepada orang tersebut untuk menjadi responden penelitian, peneliti juga dapat menitipkan instrumen penelitian tersebut pada toko atau gerai yang menjadi objek penelitian (Kuncoro, 2013). Penentuan ukuran sampel dalam penelitian ini yaitu menggunakan perbandingan observasi untuk setiap parameter yaitu 1:5 yang berarti setiap satu pernyataan minimal harus dijawab oleh 5 responden pada kuesioner penelitian dengan jumlah 22 pernyataan maka minimum sampel yang diambil dalam penelitian ini adalah sebanyak 110 sampel (Hair et al., 2012). Penelitian ini menggunakan 200 sampel dari hasil penyebaran kuesioner yang dilakukan oleh peneliti di store penjualan sepatu olahraga yang terletak di beberapa pusat perbelanjaan yang ada di kota Batam, penelitian ini dilakukan selama bulan Januari sampai dengan bulan Juni tahun 2017.

\section{PEMBAHASAN}

Berdasarkan 200 set kuesioner yang disebarkan, kuesioner yang dikembalikan dan dapat digunakan yaitu sebanyak 188 set kuesioner. Penyebaran kuesioner disebarkan oleh peneliti kepada konsumen yang berkunjung ke gerai penjualan sepatu olahraga seperti gerai Nike di Mega Mall, gerai Adidas di Nagoya Hill, kemudian gerai Sport Station di Nagoya Hill dan Kepri Mall. Berikut tabel 2 yang menjelaskan data jumlah kuesioner yang disebarkan dan diterima kembali.

Tabel 2

Tabel Distribusi Kuesioner

\begin{tabular}{lc}
\hline \multicolumn{1}{c}{ Keterangan } & $\begin{array}{c}\text { Jumlah } \\
\text { Kuesioner }\end{array}$ \\
\hline Kuesioner disebarkan & 200 \\
Kuesioner diterima & 188 \\
Kuesioner tidak lengkap & 12 \\
Total & 200 \\
\hline Sumber: Data primer diolah $(2017)$ &
\end{tabular}

Sumber: Data primer diolah (2017)

Tabel 3

Analisa Deskriptif Responden

\begin{tabular}{lcc}
\hline Deskriptif & Jumlah & $\begin{array}{c}\text { Persentase } \\
(\boldsymbol{\%})\end{array}$ \\
\hline 18-29 tahun & 146 & 77,7 \\
\hline
\end{tabular}

\begin{tabular}{lcc}
\hline 30-49 tahun & 42 & 22,3 \\
SD & 2 & 1,1 \\
SMP & 2 & 1,1 \\
SMA/SMK & 126 & 67,0 \\
Sarjana & 58 & 30,9 \\
Pegawai Swasta & 67 & 35,6 \\
Wiraswasta & 36 & 19,1 \\
Pegawai Negeri & 2 & 1,1 \\
Pelajar atau & 79 & 42,0 \\
Mahasiswa & 2 & 1,1 \\
Akademisi & 2 & 1,1 \\
Ibu Rumah Tangga & & \\
2-5 juta & 89 & 47,3 \\
5-10 juta & 68 & 36,2 \\
$>10$ juta & 31 & 16,5 \\
\hline Suta
\end{tabular}

Sumber: Data primer diolah (2017)

Berdasarkan analisa deskriptif responden pada tabel 3, usia responden dalam penelitian ini yaitu $18 \mathrm{~s} / \mathrm{d} 29$ tahun berjumlah 146 responden dengan persentase $77,7 \%$, kemudian responden yang berusia $30 \mathrm{~s} / \mathrm{d} 49$ tahun berjumlah 42 responden dengan persentase $22,3 \%$. Responden yang berusia $18 \mathrm{~s} / \mathrm{d} 29$ tahun lebih mendominasi dalam penelitian ini, hal ini dikarenakan banyaknya kunjungan dari konsumen muda ataupun remaja-remaja yang selalu update mengenai penampilan dan gaya berpakaian, sehingga sepatu sport seperti Nike, Adidas, Reebook, Converse memang menjadi incaran mereka. Penelitian yang dilakukan oleh (Hung et al., 2011) juga didominasi oleh responden atau konsumen muda yang berusia $20 \mathrm{~s} / \mathrm{d} 30$ tahun, sehingga hal ini mendukung hasil deskripti usia responden dalam penelitian ini.

Berdasarkan tingkat pendidikan dari responden pada tabel dalam penelitian ini, terdapat responden dengan tingkat pendidikan SD sebesar 2 responden $(1,1 \%)$, dan tingkat pendidikan SMP sebanyak 2 responden (1,1\%). Dalam penelitian ini responden dengan tingkat pendidikan SD dan SMP sangat rendah dikarenakan pada penelitian ini meneliti mengenai produk branded, dimana pada kondisi saat ini lebih didominasi oleh masyarakat yang berpendidikan tinggi sehingga mereka lebih memiliki pekerjaan yang menjanjikan dan secara otomatis pendapatan mereka lebih tinggi, sebenarnya beberapa yang berpendidikan SD dan SMP mampu secara finansial tetapi tidak mewakili. Kemudian tingkat pendidikan SMA/SMK sebanyak 126 responden $(67,0 \%)$, kemudian responden dengan tingkat pendidikan Sarjana sebanyak 58 responden $(30,9 \%)$. Jumlah responden yang paling besar berdasarkan tingkat pendidikan terakhir didominasi oleh responden yang memiliki tingkat SMA/SMK sebagai pendidikan terakhir, pada penelitian (Hung et al., 2011) juga didominasi oleh konsumen yang berpendidikan terakhir graduate (SMA/SMK). Responden yang memiliki pendapatan sebesar 2 s/d 5 juta berjumlah 89 responden $(47,3 \%)$, pendapatan sebesar $5 \mathrm{~s} / \mathrm{d} 10$ 
juta berjumlah 68 responden $(36,2 \%)$, kemudian responden yang memiliki pendapatan sebesar $>10$ juta berjumlah 31 responden (16,5\%). Pada penelitian ini responden yang memiliki tingkat pendapatan sebesar $2 \mathrm{~s} / \mathrm{d} 5$ juta lebih mendominasi dikarenakan pada analisis sebelumnya yaitu di status pekerjaan responden lebih didominasi oleh responden yang bekerja sebagai pelajar atau mahasiswa sehingga hal ini menjadi faktor yang mempengaruhi pendapatan, dimana pelajar atau mahasiswa yang juga merangkap sebagai pekerja rata-rata memiliki pendapatan di kisaran 2 s/d 5 juta.

\section{Validitas dan Reliabilitas}

Hasil uji validitas dalam penelitian ini yaitu variabel merek mewah menunjukkan nilai AVE berada diatas 0,5 yaitu sebesar 0,527 tanpa ada indikator dari variabel merek mewah yang di drop. Variabel pengaruh sosial menunjukkan nilai AVE berada diatas 0,5 yaitu sebesar 0,569 tanpa ada indikator dari variabel pengaruh sosial yang di drop. Variabel kebanggaan menunjukkan nilai AVE berada diatas 0,5 yaitu sebesar 0,580 , tanpa ada indikator dari variabel kebanggaan yang di drop. Kemudian variabel niat pembelian menunjukkan nilai AVE berada diatas 0,5 yaitu sebesar 0,697, tanpa ada indikator dari variabel niat pembelian yang di drop. Dari hasil uji validitas terhadap semua 22 item pernyataan dari kuesioner penelitian, maka dapat disimpulkan valid karena semua nilai factor loading berada diatas 0,5 (Ghozali, 2013).

Hasil uji reliabilitas menunjukkan bahwa nilai Composite Reliability untuk variabel merek mewah yaitu sebesar 0,908, untuk variabel pengaruh sosial yaitu sebesar 0,867, kemudian untuk variabel kebanggaan yaitu sebesar 0,873 , dan untuk variabel niat pembelian yaitu sebesar 0,872. Dari penjelasan tersebut dan pemaparan hasil uji reliabilitas pada tabel 4 maka semua variabel dalam penelitian ini dinyatakan reliabel dikarenakan nilai Composite Reliability variabel tersebut berada diatas 0,70 .

\section{Tabel 4}

Hasil Uji Validitas

\begin{tabular}{lll}
\hline Variabel & AVE & Kesimpulan \\
\hline Merek Mewah & 0,527 & Valid \\
Pengaruh Sosial & 0,569 & Valid \\
Kebanggaan & 0,580 & Valid \\
Niat Pembelian & 0,697 & Valid \\
\hline
\end{tabular}

Sumber: Data primer diolah (2017)

Tabel 5

Hasil Uji Reliabilitas

\begin{tabular}{lll}
\hline Variabel & $\begin{array}{l}\text { Composite } \\
\text { Reliability }\end{array}$ & Kesimpulan \\
\hline Merek Mewah & 0,908 & Reliabel \\
\hline
\end{tabular}

\begin{tabular}{lll}
\hline Pengaruh Sosial & 0,867 & Reliabel \\
Kebanggaan & 0,873 & Reliabel \\
Niat Pembelian & 0,872 & Reliabel \\
\hline
\end{tabular}

Sumber: Data primer diolah (2017)

\section{Pengujian Model}

H1 Merek Mewah berpengaruh positif dan signifikan terhadap Niat Pembelian.

Merek mewah memiliki peranan dalam mempengaruhi niat pembelian konsumen dalam membeli suatu produk, merek menjadi pertimbangan oleh konsumen dalam membeli suatu produk. Pasaran merek mewah tersendiri telah melebihi lebih dari 200 Milyar Euro di tahun 2014 (D’Arpizio et al., 2014). Dalam penelitian ini para responden cenderung membeli sepatu olahraga seperti Nike, Adidas, Reebook, dan Converse dikarenakan para responden memang sudah tidak asing mendengar sepatu olahraga branded tersebut sehingga dalam membeli produk tersebut, niat pembelian sudah muncul dari konsumen tersebut. Beberapa penelitian yang menyatakan bahwa merek mewah berpengaruh terhadap niat pembelian yaitu penelitian yang telah dilakukan oleh Thwaites dan, (Cheah \& Phau, 2015), (Hung et al., 2011), (Knight \& Young Kim, 2007), (P.Berthon, L.Pitt, M.Parent, 2009), (Chang, Lu, Su, Lin, \& Chang, 2011).

Hubungan antara pengaruh sosial dengan niat pembelian sebagai variabel dependen menunjukkan nilai $t$-statistic sebesar 4,451 yang artinya bahwa terdapat hubungan yang positif dan signifikan antara variabel pengaruh sosial dengan variabel niat pembelian dikarenakan nilai dari tstatistic lebih besar dari 1,96 sehingga hipotesis kedua dalam penelitian ini dapat diterima.

H2 Pengaruh sosial berpengaruh positif dan signifikan terhadap niat pembelian.

Konsumen dalam membeli suatu produk tidak terlepas dari adanya pengaruh sosial. Kondisi di Batam sebagai kota yang maju meningkatkan gaya hidup sosial, para konsumen tidak terlepas dari kehidupan sosialita yang berkembang pesat di Batam. Menurut Solomon (1983) dalam (Cheah \& Phau, 2015), konsumen yang memiliki niat pembelian terhadap suatu produk tentunya tidak terlepas dari pengaruh sosial, seperti dari pengaruh teman-teman ataupun karena dari suatu perkumpulan sehingga seseorang akan terpengaruh untuk membeli produk tersebut. Hipotesis kedua yang menyatakan bahwa pengaruh sosial berpengaruh positif dan signifikan sejalan dengan penelitian yang dilakukan sebelumnya oleh (Amaldoss \& Jain, 2005), (Cheah \& Phau, 2015), (Hung et al., 2011), (Bian \& Moutinho, 2011), (Esmaeilpour,2015). 
Tabel 6

Hasil Uji Pengaruh Langsung (Direct Effect) Tanpa Mediasi $\mathbf{X} \rightarrow \mathbf{Y ~ ( c ) ~ / ~ D i r e c t ~ w i t h o u t ~ B e t a ~ T - S t a t i s t i c ~ K e s i m p u l a n ~}$ mediation \begin{tabular}{ll|l|l|l|}
\hline Merek Mewah $\rightarrow$ Niat Pembelian & 0,206 & 2,670 & H1: +/Signifikan
\end{tabular} $\begin{array}{llllll}\text { Pengaruh Sosial } \rightarrow \text { Niat Pembelian } & 0,303 & 4,451 & \text { H2: +/Signifikan }\end{array}$ Sumber: Data primer diolah (2017)

H3 Merek mewah berpengaruh positif dan signifikan terhadap kebanggaan.

Memiliki produk dengan merek mewah memiliki suatu kebanggaan sendiri bagi konsumen. (d'Astous \& Chnaoui, 2002) menyatakan bahwa konsumen yang membeli produk sepatu olahraga seperti Nike, Adidas, Reebook, dan Converse memiliki rasa kebanggaan karena produk tersebut adalah produk dengan merek mewah (branded) kemudian juga dapat dipakai sebagai fashion daily bases. Menurut (Doss F., 2013) melakukan penelitian pada konsumen muda yang menyukai produk dengan merek mewah (young luxury consumer) mengemukakan bahwa konsumen muda yang menginginkan (desire) untuk memiliki produk dengan merek mewah, hal ini dikarenakan adanya rasa kebanggaan (vanity) dalam memiliki produk dengan merek mewah. Hasil hipotesis dalam penelitian ini juga didukung oleh penelitian yang dilakukan oleh (Turunen \& LeipämaaLeskinen, 2015), (Chang et al., 2011), (Doss F.,
2013), (Cheah \& Phau, 2015). Kemudian dapat kita lihat juga bahwa antara variabel pengaruh sosial terhadap variabel kebanggaan sebagai variabel intervening terdapat pengaruh yang positif dan signifikan, dimana nilai perolehan tstatistic yaitu sebesar 7,906 lebih besar dari 1,96, nilai ini lebih besar dari nilai t-statistic yang seharusnya sehingga dapat disimpulkan bahwa hipotesis keempat dalam penelitian ini diterima.

H4 Pengaruh sosial berpengaruh positif dan signifikan terhadap kebanggaan.

Dalam memiliki suatu produk bermerek mewah akan menimbulkan suatu perasaan bangga dalam memilikinya, dalam penelitian yang dilakukan oleh Durvasula et al. (2001) dalam (Cheah \& Phau, 2015) mengemukakan bahwa kebanggaan (vanity) memiliki pengaruh yang positif dan signifikan terhadap niat pembelian konsumen dalam membeli produk bermerek mewah. Hal ini sejalan dengan penelitian yang dilakukan oleh (I.Cheah, I.Phau, C.Chong, 2015), (Hung et al., 2011), (Kapferer \& Valette-Florence, 2016), (Walley, Custance, Copley, \& Perry, 2013).

Tabel 7

Hasil Uji Pengaruh Tidak Langsung (Indirect Effect) Dengan Variabel Intervening

\begin{tabular}{|l|c|c|c|}
\hline $\mathbf{X} \rightarrow \mathbf{M}(\mathbf{a}) /$ indirect effect & Beta & T-Statistic & Kesimpulan \\
\hline Merek Mewah $\rightarrow$ Kebanggaan & 0,491 & 10,139 & H3: +/Signifikan \\
Pengaruh Sosial $\rightarrow$ Kebanggaan & 0,432 & 7,906 & H4: +/Signifikan \\
\hline
\end{tabular}

Sumber: Data primer diolah (2017)

Tabel 8

Hasil Uji Pengaruh Tidak Langsung (Indirect Effect) Variabel Intervening dengan Variabel Dependen

\begin{tabular}{|l|c|l|l|}
\hline $\mathbf{M} \rightarrow \mathbf{Y}(\mathbf{b}) /$ Indirect effect & Beta & T-Statistic & Kesimpulan \\
\hline Kebanggaan $\rightarrow$ Niat Pembelian & 0,308 & 3,649 & H5: +/Signifikan \\
\hline Sumber: Data primer diolah $(2017)$ & & &
\end{tabular}

Tabel 9

Hasil Uji Pengaruh Langsung (Direct Effect) dengan Variabel Intervening

\begin{tabular}{|c|c|c|c|}
\hline $\begin{array}{l}\mathrm{X} \rightarrow \mathrm{Y}\left(\mathrm{c}^{\prime}\right) /(\mathrm{X} \rightarrow \mathrm{M} \cdot \mathrm{M} \rightarrow \mathrm{Y}) \text { Direct } \\
\text { effect with mediation }\end{array}$ & Beta & T-Statistic & Kesimpulan \\
\hline $\begin{array}{l}\text { (Merek Mewah } \rightarrow \quad \text { Kebanggaan) } \\
\text { (Kebanggaan } \rightarrow \text { Niat Pembelian) }\end{array}$ & 0,15 & 36,9 & \\
\hline $\begin{array}{l}\text { (Pengaruh Sosial } \rightarrow \text { Kebanggaan) } \\
\text { (Kebanggaan } \rightarrow \text { Niat Pembelian) }\end{array}$ & 0,13 & 28,8 & H7: +/Signifikan \\
\hline
\end{tabular}

Sumber: Data Primer diolah (2017) 
H5 Kebanggaan berpengaruh positif dan signifikan terhadap niat pembelian.

Pada penjelasan yang dipaparkan tabel 8 bahwa adanya keterkaitan antara faktor-faktor yang mempengaruhi kebanggaan sehingga dalam proses selanjutnya akan berpengaruh terhadap niat pembelian. Menurut Durvasula et al. (2001) dalam (Cheah \& Phau, 2015) mengemukakan bahwa kebanggaan (vanity) memiliki pengaruh yang positif dan signifikan terhadap niat pembelian konsumen dalam membeli produk bermerek mewah. Beberapa penelitian yang mendukung yaitu penelitian yang dilakukan oleh (Chang et al., 2011), (Cheah \& Phau, 2015), (Hung et al., 2011). H6 Merek mewah berpengaruh positif dan signifikan terhadap niat pembelian dengan kebanggaan sebagai variabel intervening.

Kebanggaan muncul dari niat pembelian terhadap merek mewah, penelitian-penelitian sebelumnya telah memberikan identifikasi bahwa merek mewah memberikan rasa kebanggaan terhadap konsumen dalam memilikinya, kemudian juga memberikan kenyamanan dalam menggunakannya. Sebelumnya (Gao et

al. 2009) menyatakan bahwa merek mewah seperti merek mewah pada produk sepatu, baju, jam tangan memberikan image kepada konsumen yang menggunakannya sehingga memberikan suatu rasa kebanggaan dan hal ini mendorong niat pembelian dari konsumen.

Hasil penelitian pada tabel 9 menunjukkan bahwa kebanggaan sebagai variabel intervening berpengaruh secara positif dan signifikan antara merek mewah dengan niat pembelian (path $\mathrm{x} \rightarrow \mathrm{m}$ • path $\mathrm{m} \rightarrow \mathrm{y}$ ), nilai $\mathrm{t}$ dari hasil pengolahan data menunjukkan sebesar 36,9 diperoleh dari hasil perkalian antara nilai $t$ dari independen ke mediasi dan mediasi ke dependen. Hal ini didukung dengan penelitian yang dilakukan oleh (Cheah \& Phau, 2015), (I.Cheah, I.Phau, C.Chong, 2015), (Hung et al., 2011), (Chang et al., 2011) yang menyatakan bahwa kebanggaan berperan secara intervening antara merek mewah dan niat pembelian.

H7 Pengaruh sosial berpengaruh positif dan signifikan terhadap niat pembelian dengan kebanggaan sebagai variabel intervening.

Peranan kebanggaan sebagai variabel intervening antara pengaruh sosial dan niat pembelian tidak terpisah dan saling mempengaruhi, dikarenakan hal yang mendorong niat pembelian konsumen untuk merek mewah adalah pengaruh sosial, kemudian dari pengaruh sosial tersebut memunculkan rasa kebanggaan karena memiliki merek mewah dan adanya social acceptance. (Truong, McColl, \& Kitchen, 2010) menyatakan bahwa rasa kebanggaan dalam bentuk kepuasan diri muncul dari adanya pengaruh sosial sehingga mendorong konsumen untuk melakukan niat pembelian merek mewah. Hasil penelitian pada tabel 9 menunjukkan bahwa kebanggaan sebagai variabel intervening berpengaruh secara positif dan signifikan antara pengaruh sosial dengan niat pembelian $($ path $\mathrm{x} \rightarrow \mathrm{m} \cdot$ pathm $\rightarrow \mathrm{y})$, nilai $\mathrm{t}$ dari hasil pengolahan data menunjukkan sebesar 28,8 diperoleh dari hasil perkalian antara nilai $\mathrm{t}$ dari independen ke mediasi dan mediasi ke dependen. Hasil penelitian ini didukung oleh penelitian yang telah dilakukan oleh (Cheah \& Phau, 2015), (Truong et al., 2010), (Alexander \& Contreras, 2016).

\section{KESIMPULAN}

Penelitian ini memberikan hasil bahwa variabel intervening kebanggaan berpengaruh secara parsial (partially mediated) terhadap niat pembelian sebagai variabel dependen di dalam penelitian ini. Hal ini dibuktikan dalam pengujian mediasi dimana variabel independen dalam penelitian ini secara langsung berpengaruh positif dan signifikan tanpa melalui variabel intervening. Menurut Wang dan Waller (2006) di dalam (Hung et al., 2011) dimana dalam membeli produk bermerek mewah, konsumen akan memiliki rasa bangga dalam memilikinya sehingga kebanggaan berpengaruh terhadap niat pembelian. Penelitian ini juga menjelaskan mengenai kondisi pemasaran khususnya pada produk sepatu olahraga branded seperti Nike, Adidas, Reebook, dan Converse yang menjadi suatu produk yang sangat terkenal di kalangan konsumen (Chiu \& Leng, 2016), dalam penelitian ini yang didominasi oleh konsumen yang berumur muda atau disebut sebagai konsumen muda yang lebih sering memakai produk branded, hal ini senada dengan penelitian yang dilakukan oleh (Doss F., 2013) yang meneliti mengenai konsumen muda di Amerika yang memberikan hasil penelitian bahwa konsumen muda (young luxury consumer) saat ini lebih menyukai akan produk-produk yang branded ataupun luxury, sedangkan menurut (Alexander \& Contreras, 2016) menyatakan bahwa saat ini konsumen muda lebih mewakili dan memiliki nilai yang tinggi dalam konsumsi produk bermerek mewah. Penelitian ini juga membuktikan bahwa konsumen muda di kota Batam sangat menyukai produk sepatu olahraga bermerek mewah atau branded seperti Nike, Adidas, Reebook, Converse. Konsumen muda saat ini bukan hanya berbeda dari generasi sebelumnya, pada saat ini mereka memiliki kekuatan atau niat pembelian yang tinggi kemudian satu hal unik yang membuat mereka menjadi kekuatan baru di pasar dalam membeli atau mengkonsumsi produk-produk mewah yaitu konsumen muda sangat terpengaruh jika mereka melihat sesuatu yang mereka inginkan maka hal ini kemudian membentuk niat pembelian yang kuat, hal ini senada dengan penelitian yang dilakukan oleh (Perry \& Kyriakaki, 2014), (Hung et al., 2011), (Wong \& Malone, 2016), (Han, Nunes, \& Drèze, 2010). Dalam penerapannya, hal ini 
menjadi suatu kesadaran merek yang ditunjukkan oleh konsumen muda di kota Batam sehingga hal ini dapat dijadikan strategi bagi produsen yang ingin menargetkan penjualan sepatu olahraga branded khususnya di kota Batam.

\section{DAFTAR PUSTAKA}

Alexander, B., \& Contreras, L. O. (2016). Interindustry creative collaborations incorporating luxury fashion brands. Journal of Fashion Marketing and Management: An International Journal, 20(3), 254-275. https://doi.org/10.1108/JFMM-09-20150075

Amaldoss, W., \& Jain, S. (2005). Pricing of Conspicuous Goods: A Competitive Analysis of Social Effects. Journal of Marketing Research, 42(1), 30-42. https://doi.org/10.1509/jmkr.42.1.30.56883

Bian, X., \& Moutinho, L. (2011). The role of brand image, product involvement, and knowledge in explaining consumer purchase behaviour of counterfeits. European Journal of Marketing, 45(1/2), 191-216. https://doi.org/10.1108/0309056111109565 8

Chang, W., Lu, L., Su, H., Lin, T. A., \& Chang, K. (2011). The relationship among consumer vanity trait, materialism and fashion anxiety, 5(May), 3466-3471. https://doi.org/10.5897/AJBM10.472

Cheah, I., \& Phau, I. (2015). Effects of "owned by" versus "made in" for willingness to buy Australian brands. Marketing Intelligence \& Planning, 33(3), 444-468. https://doi.org/10.1108/MIP-01-2014-0016

Chiu, W., \& Leng, H. K. (2016). Consumers' intention to purchase counterfeit sporting goods in Singapore and Taiwan. Asia Pacific Journal of Marketing and Logistics, 28(1), 23-36. https://doi.org/10.1108/APJML-022015-0031

D’Arpizio, C., Levato, F., Zito, D., \& De Montgolfier, J. (2014). LUXURY GOODS WORLDWIDE MARKET STUDY FallWinter 2014: The rise of the borderless consumer. Bain \& Company, Inc.

d'Astous, A., \& Chnaoui, K. (2002). Consumer Perception of Sports Apparel: The Role of Brand Name, Store Name, Price, and Intended Usage Situation. International Journal of Sports Marketing and Sponsorship, 4(2), 14-31. https://doi.org/10.1108/IJSMS-04-02-2002B004

Doss F., R. T. (2013). Journal of Fashion Marketing and Management: An International Article information: Fashion
Marketing and Management, 17(2), 141159.

https://doi.org/https://doi.org/10.1108/JFM M-02-2011-0045

Esmaeilpour, F. (2015). Article information: Journal of Fashion Marketing and Management, 19(4), 467-484. https://doi.org/10.1108/IJBM-07-20130069

G. Timperio, Tan K.Chuan, L.Fratocchi, S. P. (2016). The impact of ethnicity on luxury perception: the case of Singapore's Generation Y. Int J Logistics Management, 28(2), 217-233. https://doi.org/10.1108/0957409091095486 4

Gao, L., Norton, M. J. T., Zhang, Z., \& Kin-man To, C. (2009). Potential niche markets for luxury fashion goods in China. Journal of Fashion Marketing and Management: An International Journal, 13(4), 514-526. https://doi.org/10.1108/1361202091099137 6

Godey, B., Pederzoli, D., Aiello, G., Donvito, R., Wiedmann, K., \& Hennigs, N. (2013). A cross-cultural exploratory content analysis of the perception of luxury from six countries. Journal of Product \& Brand Management, 22(3). https://doi.org/10.1108/JPBM-02-20130254

Han, Y. J., Nunes, J. C., \& Drèze, X. (2010). Signaling Status with Luxury Goods: The Role of Brand Prominence. Journal of Marketing, 74(4), 15-30. https://doi.org/10.1509/jmkg.74.4.15

Hung, K., Huiling Chen, A., Peng, N., Hackley, C., Amy Tiwsakul, R., \& Chou, C. (2011). Antecedents of luxury brand purchase intention. Journal of Product \& Brand Management, 20(6), 457-467. https://doi.org/10.1108/1061042111116660 3

I.Cheah, I.Phau, C.Chong, A. S. S. (2015). Antecedents and outcomes of brand prominence on willingness to buy luxury brands. Journal of Fashion Marketing and Management, 19(4), 402-415. https://doi.org/10.1108/IJBM-07-20130069

Kapferer, J.-N., \& Valette-Florence, P. (2016). Beyond rarity: the paths of luxury desire. How luxury brands grow yet remain desirable. Journal of Product \& Brand Management, 25(2), 120-133. https://doi.org/10.1108/JPBM-09-20150988

Knight, D. K., \& Young Kim, E. (2007). Japanese consumers' need for uniqueness. Journal of Fashion Marketing and Management: An 
International Journal, 11(2), 270-280. https://doi.org/10.1108/1361202071075142 8

Martinez, B., \& Kim, S. (2012). Predicting purchase intention for private sale sites. Journal of Fashion Marketing and Management: An International Journal, 16(3), 342-365. https://doi.org/10.1108/1361202121124608 0

P.Berthon, L.Pitt, M.Parent, J. P. B. (2009). Aesthetics and Ephemerality: observing and preserving the luxury brand. California Management Review, 52(1), 45-66. https://doi.org/10.1525/cmr.2009.52.1.45

Park, H., Rabolt, N. J., \& Sook Jeon, K. (2008). Purchasing global luxury brands among young Korean consumers. Journal of Fashion Marketing and Management: An International Journal, 12(2), 244-259. https://doi.org/10.1108/1361202081087491 7

Perry, P., \& Kyriakaki, M. (2014). The decisionmaking process of luxury fashion retail buyers in Greece. Journal of Fashion Marketing and Management: An International Journal, 18(1), 85-106. https://doi.org/10.1108/JFMM-06-20120030

Srinivasan, R., Srivastava, R. K., \& Bhanot, S. (2014). A Study of the antecedents of purchase decision of luxury brands. IOSR Journal of Business and Management Ver. II, 16(5), 2319-7668. Retrieved from www.iosrjournals.org
Teimourpour, B., \& Heidarzadeh Hanzaee, K. (2011). The impact of culture on luxury consumption behaviour among Iranian consumers. Journal of Islamic Marketing, 2(3), 309-328. https://doi.org/10.1108/1759083111116482 2

Truong, Y., McColl, R., \& Kitchen, P. J. (2010). Uncovering the relationships between aspirations and luxury brand preference. Journal of Product \& Brand Management, 19(5), 346-355. https://doi.org/10.1108/1061042101106858 6

Turunen, L. L. M., \& Leipämaa-Leskinen, H. (2015). Pre-loved luxury: identifying the meanings of second-hand luxury possessions. Journal of Product \& Brand Management, 24(1), 57-65. https://doi.org/10.1108/JPBM-05-20140603

Walley, K., Custance, P., Copley, P., \& Perry, S. (2013). The key dimensions of luxury from a UK consumers' perspective. Marketing Intelligence \& Planning, 31(7), 823-837. https://doi.org/10.1108/MIP-09-2012-0092

Wong, W., \& Malone, T. (2016). Contribution of vanity to consumer apparel advertising perception. Journal of Fashion Marketing and Management: An International Journal, 20(1),

54-71. https://doi.org/10.1108/JFMM-06-20150045 